\title{
THE MIRROR FRAMEWORK: A CRITICAL TEXT ANALYSIS PEDAGOGICAL TOOL FOR THE FOREIGN LANGUAGE (FL) LEARNING CONTEXT
}

\author{
GEORGE CREMONA ${ }^{1}$ \\ UNIVERSITY OF MALTA
}

\begin{abstract}
Textbooks used in foreign language (FL) classrooms, together with other authentic printed and/or audio-visual texts, serve to familiarise FL learners with the culture of the country where the target language being taught is used as L1 (Unesco, 2007). This motivates teachers to seek instructional tools through which they can analyze the way the 'foreign' country is represented in the texts they intend to use in class.

Linked to this, the paper will first present one of the most popular text analysis frameworks which FL teachers refer to when doing such text analysis. The popularity of this particular text analysis framework links to the fact that it was designed by Mike Byram (1993) whose work is seminal in the fields of FL teaching and intercultural competences. Because of Byram's acclaimed reputation, very often FL teachers just use his framework without ample critical reflection.

In response to this, while pointing out the strengths of Byram's text analysis framework, this paper intends to go one step further and critically evaluates Byram's (1993) model. The paper reacts by suggesting that a multimodal social semiotic focus may help to add FL teacher criticality when using Byram's model. This is one of the contributions to the field of FL teaching and learning, since such multimodal social semiotic elements rarely feature in text analysis frameworks contemporary FL teachers frequently refer to.

As a conclusion, the paper presents a step by step explanation of the original MIRROR framework which FL teachers can use critically as an instructional tool while conducting the analysis of cultural representations presented in the FL texts they have at hand.
\end{abstract}

Key words: Material development, Foreign Language teaching and learning, Multidmodality

\section{RESUMEN}

Los libros de texto empleados en las aulas de lengua extranjera (LE), junto con otros textos auténticos impresos y/o audiovisuales, sirven para familiarizar a los aprendices de LE con la cultura del país donde la lengua meta que se enseña se utilize como L1 (Unesco, 2007). Esto motiva a los docentes a buscar herramientas de instrucción a través de las cuales puedan analizar la representación del país 'extranjero' en los textos que aspiran utilizar en clase.

Relacionado con esto, el artículo presentará primero uno de los marcos de análisis de texto más populares a los que se refieren los profesores de LE al hacer tal análisis de texto. La popularidad de este marco de análisis de texto se debe al hecho de que fue diseñado por Mike Byram (1993), cuyo trabajo es seminal en los campos de la enseñanza de LE y las competencias interculturales. Debido a la aclamada reputación de Byram, muy a menudo los profesores de LE solo usan su marco sin una amplia reflexión crítica.

En respuesta a esto, a pesar de señalar los puntos fuertes del marco de análisis de texto de Byram, este artículo pretende dar un paso más y evaluar críticamente el modelo de Byram (1993). El artículo reacciona al sugerir que un enfoque semiótico social y multimodal puede ayudar a fomentar la criticidad del profesor de LE cuando utiliza el modelo de Byram. Esta es una de las contribuciones al campo de enseñanza y aprendizaje de LE, yaque tales elementos semióticos sociales y multimodales raramente aparecen en los marcos de análisis de textos a los que se refieren frecuentemente los profesores de LE contemporáneos.

1Email: georgeuni@gmail.com 
A modo de conclusión, el artículo presenta una explicación paso a paso del marco original MIRROR que los profesores de LE pueden utilizar de manera crítica y como herramienta de instrucción a la hora de realizar el análisis de las representaciones culturales presentadas en los textos de LE estudiados.

Palabras clave: Desarrollo de material, Enseñanza y aprendizaje de lenguas extranjeras, Multidmodalidad

\section{Introduction: Introducing Byram's text analysis attempt}

In 1993, Mike Byram edited a book called Germany - Its Representation in Textbooks for Teaching German in Great Britain (1993). This book first presents a number of articles discussing the potentialities of textbooks and their use as tools for the teaching of culture, cultural awareness and intercultural awareness. As a second step, the book then moves on to a practical text analysis exercise of five different textbook series which (back in 1993) were used to teach German as a foreign language in Great Britain.

As a preamble to the exercise of textbook analysis, the book includes a chapter written by Byram himself (from page 31 to page 40) through which an explanation of the criteria used for the textbook evaluation proposed is presented. Byram and his colleagues evaluated the five textbook series by asking the following three questions:

1. To what extent does the author of the particular textbook realise his/her conception of cultural studies?

2. To what extent does the course give opportunity to explore the National Curriculum 'areas of experience'?

3. To what extent does the textbook satisfy: educational potential?

- How effective is the textbook in improving the linguistic and cultural knowledge of the student?

Does the content provide opportunity to promote intercultural learning and political literacy (or 'education for citizenship')?

- accuracy?

- Is the factual detail accurate?

- realism?

Is the culture presented in a multi-perspectival way so as to relate the world of the textbook to the real world of Germany and German-speaking countries, irrespective of whether techniques are 'realistic', 'fantastic' or other?

- $\quad$ Are stereotyping, prejudices, bias and one-sidedness avoided?

- representativeness?

Byram suggests that evaluators doing text analysis should continuously check whether the minimum content is included throughout the particular series being scrutinised. In Byram's view, this minimum content includes a set of cultural categories, topics and information which:

must give learners empathetic understanding of (part of) the culture, and an increased understanding of learners' own culture ...

aims to promote positive attitudes towards other people and reflection on one's own culture...

should show that the social group to be studied is a 'given' insofar as tradition requires that if for example, German is the language then "the Germans" are the group... we have to assume therefore that there is an identifiable German culture - shared knowledge and meanings - common to all those people who call themselves German (p. 32). 
Byram proposes eight of these minimum content categories which in his view should be present in any GFL textbook which aims to fulfill the criteria of representativeness:

- $\quad$ information about social identity and social groups

- $\quad$ information about social interaction

- information about belief and behaviour

- $\quad$ information about social and political institutions

- $\quad$ information about socialisation and the life cycle

- $\quad$ information about national history

- $\quad$ information about national geography

- information about stereotypes and national identity.

\section{Byram's application of the text analysis criteria}

In the second part of the book, Byram and a number of other British and German colleagues, use the above-mentioned text analysis criteria to analyse five different GFL textbook series. For each series the authors first produce a long list through which they describe what in their views were the cultural elements included per chapter. Each list (per textbook) is over ten pages long (see sample in Table1 below). 
Table 1: A sample taken from the list which opens each textbook analysis chapter (a selection from Byram, 1993, p. 143)

\section{List of Cultural References: \\ Los geht'sBook 1}

Lektion 5: $\quad$ Everyday Life, Work and Leisure

page 92:Busy housewife's day.

page 96: Job sharing and a cartoon illustrating a housewife's long hours. Husband has to look after the children because she goes out, having done her hours of work looking after them.

\section{Lektion 6: $\quad$ Travel}

page 98:Collage by a Japanese school boy of how he sees Germany.

page 99:Different views of Germany (rather stereotypical).

page 102f: Austrian hotels (Schilling is currency).

page 105: $\quad$ Areas of Austria, but rather superficial.

page 107: $\quad$ Transport in Germany. Maps showing rail and motorway network and airports.

page 108: $\quad$ Authentic-looking railway timetables.

page 109: $\quad$ Picture of German railway official.

page 114: $\quad$ Authentic-looking holiday brochure.

page 115: Different types of tourists.

page 116: Holiday tips. Different types of holidays that are on offer.

Lektion 7: $\quad$ Buying Presents

page 133: $\quad$ Fotomesse Köln.

page 134: $\quad$ Problems of small businesses.

page 135: $\quad$ Young people's spending habits (rather dated 1976 survey). 
After the presentation of the compiled list, the authors then move on to answer the three questions proposed by Byram as the criteria for text analysis (see questions in previous Section,i.e. the introduction of this paper). This in each case is done twice, first by a British (i.e. non native German) academic and later by a German academic. The two interpretations per textbook are presented as separate entities.

\section{Taking Byram's initiative further: My critique of Byram's text analysis}

Once I keep reflecting about Byram's criteria, I realise that whereas Byram raised a number of valid points, I can still identify various debatable issues in the way the author and his colleagues have conducted the text analysis of the five selected GFL textbook series. My reasoning agrees with what Byram(1993) himself suggested more than once, namely that:

[Our method of text analysis] no doubt will itself be subject to debate... (p. 36).

Although we have set our expectations high, there is much to commend in the textbooks we examine. The purpose of our book is to provide specific comments and evaluations and also to suggest to our readers how they might consider other textbooks in their own right (p. 40).

Although we hope that these criteria will stand the test of time, we do not assume that they cannot be further refined as our research and that of other scholars and teachers progresses (pp. 195-196).

My three main concerns about the textbook analysis done by Byram and his colleagues are:

1. the non-detailed (at times superficial) initial descriptions included in the lists of cultural references at the beginning of each text analysis attempt (see sample in Table1);

2. the way different levels of analysis are interpreted simultaneously and how they end up presented at one go;

3. the way the authors formulate their interpretation(s) and how they present the final write-up.

\section{Presenting the MIRROR Framework}

Keeping these three concerns in mind, with the clear intention of refining Byram's criteria of text analysis, I designed my own text analysis framework which I have termed by the acronym MIRROR:

Monitoring available texts and choosing the actual texts for analysis;

Initial descriptive interpretation (per individual text);

Representational multimodal semiotic interpretation (per individual text);

Represented social interpretation (per individual text);

Overview of the representations of the 'foreign' country where the target language is spoken as L1 observed: presenting a detailed write up of the representations obtained per individual text. Later comparing individual trends with common trends derived from texts as a whole (where possible)

Reorganising the representations derived from the MIRROR Framework and presented in the overview (i.e. the latter step) according to the different categories proposed by the FL curriculum used within the particular learning context.

I felt that the acronym MIRROR served the framework very well, since the framework's main purpose is to investigate whether the contents of texts used to teach GFL are serving as mirrors reflecting elements from Germany which they are expected to faithfully represent (Zu and Kong, 2009) or whether they are only representing part(s) of the complex German society, intentionally and/or unintentionally leaving out other relevant parts (Gray in Block and Cameron, 2002). 
Although each step in the MIRROR framework above seems chronological and its different levels might seem separate from each other, once this framework is applied in practice, each step intertwines with the others. The framework involves its user in a continuous process of relooping(Fairclough, 2010 [2008]) in which no boundaries between different levels limit the interpretation.

\subsection{A detailed explanation of the MIRROR framework}

In these (coming) sections I intend to show how, through the design of my MIRROR framework, I specifically aimed at focusing on the three main concerns I felt I could critique Byram's text analysis criteria about. I felt I had to address these concerns and tried to refine Byram's text analysis framework through my own MIRROR framework.

My attempt - as the next sections will indicate - was facilitated through my decision to base the MIRROR framework on an adaptation of O'Regan's TACO (i.e. standing for Text as a Critical Object) model of text analysis (2006). The selection of this particular model among all others was linked to the explicit pedagogic application the model presents as well as the model's alignment with the multimodal and social perspective which the current paper is interested in.

\subsection{Addressing my first concern about Byram's textbook analysis - the initial reading of texts}

The lists of cultural references (see sample reproduce in Table 1 above) which Byram and his colleagues included at the very beginning of each textbook analysis, in my view, lack sufficient details which the readers of the textbook analysis might need to perceive the content included in each series. The way the page content is frequently minimalised to a short phrase does not help the reader to understand neither what cultural content has been included by the authors of the particular textbook, nor the way the particular content was presented in the textbook.

Another shortcoming which in my view deserves attention, is the way how even within the same list the authors act inconsistently. At times they just talk very briefly about the contents (example from the list in Table 1: Different types of tourists), at others they pass an opinion about the cultural reference (example from the list in Table 1: Different views of Germany (rather stereotypical) and at others they even include the genre the authors have used to present the particular cultural reference (example from the list in Table 1: Picture of German railway official).

4.2.1 The first level: Initial descriptive interpretation - an adaptation of O'Regan's descriptive interpretation.

In response to Byram, the MIRROR framework proposes a more organised solution through which these shortcomings could be avoided. Following O'Regan, the MIRROR framework proposes that as from the very initial readings, evaluators of texts should descriptively analyse the following features of the text at hand:

- $\quad$ thetopic(s) or the theme being presented by the text. A further analysis included is one linked to the way the topic is presented. Ways of topic presentation may include formal, informal, persuasive, aggressive, angry, friendly, humorous and comic (O'Regan, 2006, p. 192);

- $\quad$ theideal reader of the text: the type of reader for whom the text appears to be intended (O'Regan, 2006, p. 191);

thepreferred reading of the text which O'Regan describes as the apparent main message of the text and the reading which accords with the way the text seems to want to be read (O'Regan, 2006, p. 192).

With these, this paper adds genre description and analysis which O'Regan(2006) includes as part of the representative interpretation (i.e. his second stage). This shift from O'Regan was done for a purpose. 
Presenting information linked to genre clearly at the very initial stage of text analysis and not later, ensures that from the very beginning the text is set in a context. This allows the reader/interpreter to reach a more comprehensive overall initial interpretation (Sutherland, 2006).

When looking for a systematic way to analyse genre, on the one hand I was aware that:

- Genres vary quite considerably in terms of degree of stabilisation, fixity and homogenization (Fairclough, 2003, p. 66)

- We need to look for staging in analyzing texts and interactions, but not expect to always find that they are organised in terms of a clear generic structure (Fairclough, 2003, p. 72)

- There is no established terminology for genres (Fairclough, 2003, p. 66).

Despite these issues, this paper follows Fairclough's $(2003$, p. 69) two steps when handling genres:

Genre description: A description of texts or interaction distinguishing between pre-genre and disembedded genre where applicable. Quoting Fairclough, pre-genres define the most abstract categories including Narrative, Argument, Description or Conversation (Fairclough, 2003, p. 68). On the other hand, disembodied genres define somewhat less abstract categories including monologues, interviews, dialogues, picture stories, letters and others (Fairclough, 2003).

Genre analysis: looking out for three main features;

- Activity of Genre: Fairclough defines this as the answer to the question: "What are people doing?" (Fairclough, 2003, p. 70). Fairclough's question is answered adopting Habermas' (1984) distinction between activities with a communicative purpose (i.e. oriented to understanding) and/or activities with a strategic purpose (i.e. oriented at getting results).

- Social Relations between interactants: In Fairclough's words here one is looking for answers for the question "What are the social relations between people featuring in the text?" (Fairclough, 2003, p. 70). These include interactions either between organisations, between groups or between individuals. A mixture of the three is also possible. Equally helpful are Dwyer's (2009) categories of individual relations distinguishing between affiliation, friendship, relations with relations and romantic relationships.

- Communication technology required: In Fairclough's words a third question one needs to ask to have a complete genre analysis is: "What communication technology, if any, does the text or interaction depend on?"(Fairclough, 2003, p. 70). Schematically here there are four possibilities:

Two-way non-mediated: face to face conversation;

Two-way mediated: including telephone, email, video conferencing;

One-way non-mediated: lecture, etc;

One-way mediated: including print, radio, television, Internet and film (Fairclough, 2003, p. 77). 


\subsection{Addressing my second concern about Byram's textbook analysis - choosing between different levels}

A second shortcoming I could observe is how Byram and his colleagues tended not to distinguish between the analysis of the way the content is presented (i.e. the representative interpretation) and the analysis of the content itself (i.e. the content interpretation). The following are three examples where this clearly happens.

On page 25 a photo shows a man bedecked with medals, the speech balloon says ,Ich komme aus Hannover." It scarcely needs to be asked whether he is a typical citizen of Hannover, though it is equally obvious that he belongs to a distinct group in society (p. 94).

Closer to the individual student is the question on page 118, „Wies ind deine Klassen kameraden?", which places people in categories according to caricatures and adjectives. That shows some justification for stereotyping, our common need to classify individuals linguistically, even by labeling them (p. 95).

On page 79 the excellent cartoon Rotkäppchen und der Wolf is full of humorous detail, a medley of traditional and contemporary. By illustrating the possibility of bringing together the past and the present, that cartoon symbolises for me the continual practice throughout the Course of encouraging flexibility of thinking and acceptance of new and of mixed ideas, which should promote open-mindedness about cultural matters (p. 99).

As these examples illustrate, the authors frequently do not distinguish between the content presented in the textbook and how it is being presented. They tend to present the two levels together, frequently just using a sentence or two. The latter three examples are not exceptions. In fact the five pairs of text analysis included in the book, very frequently end up consisting of similar statements in which the authors combine both levels of analysis (content interpretation and content presentation) at one go. This happens with the consequence that very frequently the analysis once again ends up lacking detail and being rather disorganised due to the fact that two levels of analysis have been treated simultaneously.

In response to Byram, the MIRROR framework analyses in detail both levels and while acknowledging that they are interlinked, it still suggests that they should be analysed as separate levels.

4.3.1 The second level: Representational multimodal semiotic interpretation - an adaptation of O'Regan's representative interpretation.

This second level entails a multimodal analysis of the selected texts. To start with multimodality can be defined as:

... the use of several semiotic modes in the design of a semiotic product or event, together with the particular way in which these modes are combined (Kress and Van Leeuwen, 2001, p. 20).

The aim of this level of interpretation is to identify and highlight representations of the country where the target language is used as L1 perceived through the particular ways different semiotic modes are combined in the design of particular semiotic products (i.e. in this case the particular FL text used) or events (i.e. in this case the situations presented in the particular FL text). 
1. To reach this interpretation this paper initially highlights all the different modes included in the particular text. A mode is a culturally-shaped semiotic resource having specific potentials through which it can produce certain communicative effects and not others (Stein, 2008). These potentials are called affordances(Gibson, 1979). The contemporary digital generation (Beach and O'Brien, 2008):

increasingly likely expresses ideas using different semiotic modes, including print, visual, and audio modes, and create[s] hybrid texts that defy typical associations between modes and what they traditionally represent (Wood and Blanton, 2009, p. 476). Keeping this in mind, the traditional distinction between verbal and non-verbal modes, often treating language as a superior mode - when in fact it may not always be the case - is avoided. Aware of such a situation, this paper follows Norris' (2004) distinction between embodied and disembodied modes.

Embodied modes classify language with other modes like gesture, gaze, or posture which 'can play a super ordinate or an equal role to the mode of language in interaction, and therefore, these modes are not merely embellishments to language'(Norris, 2004, p. x).

On the other hand, disembodied modes' include among others music, print, layout, colour, clothes and any other mode deriving from the setting or material world where the interaction is happening. These too can take a super ordinate role in interaction and at times even 'overrule' embodied modes'(Norris, 2004, p. x).

2. Each of the identified modes is then analysed in the light of Kress' socio-semiotic approach (2010) and Kress and Van Leeuwen's (2006) multimodal text analysis model.

This paper follows Kress and van Leeuwen's (2006) adaptation of the theoretical notion of 'metafunction' as proposed by Halliday. In this light, the paper follows the idea that 'every semiotic fulfils both an 'ideational' function, a function of representing 'the world around and inside us' and an 'interpersonal' function, a function of enacting social interactions as social relations. All message entities texts - also attempt to present a coherent 'world of the text', what Halliday calls the 'textual' function - a world in which all the elements of the text cohere internally and which itself coheres with its relevant environment' (Kress and Van Leeuwen, 2006, p. 15).

This level initially identifies Ideational (within image) features and their effects. Later it examines Interpersonal features, therefore highlighting the interaction between image and reader (i.e. in this case myself as a reader of the texts). Lastly, it looks for the textual and layout characteristics and their influence on the reader/learners. These three steps in unison lead to the identification of various representations of the country where the target language is spoken as $L 1$ and its people perceived from each text.

3. The final step in this second representational level is to organise each representation perceived under each categories as proposed by the FL syllabus. These categories and their use primarily lead to a more organised multimodal interpretation.

\subsubsection{Level 3: Representative social interpretation - an adaptation of O'Regan's social interpretation.}

Whereas in the latter level of interpretation (i.e. Level 2) the main focus is to highlight and interpret representations of the country where the target language is spoken as L1 perceived through semiotic modesi.e. keeping the social aspects in the background, at this level (i.e. Level 3 ) there is a shift in focus. While semiotic modes still remain at the background, this time social features and practices and the representations of the particular country they present are the focus of attention. This social level poses one main question: 
Table 2: Presenting the checklist applied while conducting the social interpretation of representations formed about the 'foreign' country

Are particular social features preferred/disfavored by this particular text?

Answers the question in terms of the following social features and practices:

- Social Identity and Social Groups

- Social Interaction

- Belief and Behaviour

- Social and Political institutions

- Socialisation and the life-cycle

- National history

- National geography

Adlopted from Byram(1993, pp. 36-37)

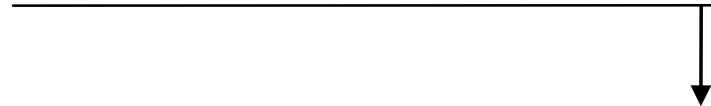

The attempt to answer the above question also aims to highlight possible discourse types, which may include discourses linked to:

- Class

- Race

- Gender

- Media language, advertisements and promotional culture

- Institutional Discourse: in institutional practices and communications

- Education: an area for reproduction of social relations, representation and identity-formation. Adopted from Blommaert (2005, pp. 26-27)

As evident from Table 2 above, this paper defines 'discourse' not merely as language-in-use. Instead of simply treated as the linguistic structures actually used by people (Brown and Yule, 1983), discourse here is treated as a general mode of semiosis which in Blommaert's words results in the analysis of 'meaningful semiotic human activity seen in connection with social, cultural, and historical patterns and developments of use' $(2005$, p. 3). Considered in this light, 'discourse can become a site of meaningful social differences, of conflict and struggle, and how this results in all kinds of social-structural effects' (2005, p. 4).

\subsection{Addressing my third concern about Byram's textbook analysis - interpretation and presentation}

Reading through the textbook analysis presented by Byram and his colleagues (1993), another concern which I could not avoid thinking about is the very striking way (at least to me) through which the authors formulate and present their interpretations. The following excerpt stands out as an exception in Byram's and colleagues' collection of textbook analysis:

What is presented (in the textbook) is accurate factually as far as I can tell, though here again a native observer is likely to be a sharper critic. This is especially so if the accuracy is reduced by omission or failure to mention part of a set or range of facts (p. 95).

Instead - more often than not - the authors seemingly present their textbook analysis using very certain statements. Below, I quote two excerpts which include examples of these statements. I use a bold font to 
present the words through which the interpretation sounds very assertive. These words frequently give the impression that this interpretation is the only valid and/or possible interpretation:

The Course strategy of relating to the viewpoint of 11 to 16 year olds works well in describing and discussing the 1933 - 1945 period. Attempting to answer the question "What was it like?" must leave many of today's readers in a state of uncomfortable uncertainty about how they themselves would have behaved in a similar circumstance. The presentation of 1933 - 45 is through frank text and stark photographs and though these have not been evaluated a larger than usual number of extended listening texts (p. 97).

From the very beginning of Book 1 there is a distinct feeling of authenticity. One of the things that greatly contribute to this is the frequent use of statistical diagrams drawn from genuine German sources. It is admirable that the grammar and exercises are kept to the same topic as the Lektion(p. 148).

Furthermore, through the way they formulate their interpretations, Byram and his colleagues frequently appear interested in revealing the intentionality of the authors or publishers of the particular FL textbook. The following excerpt is just one example (of the many included throughout Byram's edited book):

It might also be possible that authors have taken another important factor in consideration. For years the image of Germany in the minds of the majority of British people has been coloured by the two world wars, resulting in the stereotypical view that still finds expression in Britain's suspicion of such phenomena as reunification or the role of the Bundesbank. Zick Zack addresses none of these problems in any depth, possibly because the authors feel that 12 to 16 year olds cannot cope with them adequately, but more probably, because they feel that such a deeply rooted stereotype can only be countered by creating a strong impression that young people in Germany and Britain are much the same, exposed to cultural influences that differ only in minor detail (p. 174).

Whereas O'Regan's TACO model includes a fourth deconstructive level, the MIRROR FRAMEWORK proposed by this paper refrains from applying this fourth level since the texts analysed here are socioculturally mundane. The current paper's main purpose is not to treat texts as political statements or as argumentative or political texts as is common both in early CDA works (including Gruber, 1991; Mitten, 1992; Wodak et al., 1990) and in more recent others (including Krzyzanowski and Oberhuber, 2007; Triandafyllidou, Wodak and Krzanowski, 2009; Wodak, 2009). Therefore this paper, through the MIRROR framework is not interested in deconstructing arguments. Instead the paper's main focus is the mapping of representative multimodal social semiotic experiences of the 'foreign' country where the target language is spoken as L1.

While doing this mapping, in response to Byram, the MIRROR Framework includes a word of caution and suggests that textbook evaluators should refrain from (intentionally or unintentionally) presenting their textbook interpretation as exclusive or as the one and only correct possible interpretation. Similarly, in response to Byram, those using the MIRROR Framework are encouraged to remember that while doing this mapping of representative multimodal social semiotic experiences of the particular country, they should avoid intentions or targets through which they attempt to uncover or unmask hidden agendas of the designers or authors of the texts (i.e. in this case the authors, publishers and/or designers of the texts used to teach the particular FL).

\section{Conclusion: The MIRROR Framework Overview}

To sum up, what follows in Table 3 is an overview of the different (yet interlinked) elements included in the MIRROR Framework. 
Table 3: The Mirror Framework - An Overview

Monitoring of available texts and choosing the actual texts for analysis;

- Which are the sources available at hand?

- Which are the most quoted (i.e. the most popular) texts at hand?

- How are they similar?

- In what way do they differ?

- Do any of the available texts possess a particular/special feature which deserves particular attention? Why?

Initial descriptive interpretation (per individual text);

- Which topic(s) are being presented and/or discussed?

- Who is the ideal reader of the text? For who was it originally designed?

- Which genres are being used to present the text? Which are the implications linked to these particular genres used and how do these implications contribute to set/effect representations of the country where the target language taught is used as L1?

- Which representations of country (i.e. where the target language taught is used as L1) do the selected texts appear to imply after a first reading (i.e. the preferred reading)?

Representational multimodal semiotic interpretation (per individual text);

- Which are the particular sections of the selected texts which appear sequential (i.e. not as separate entities)?

- Identify all the modes - embodied and disembodied - building up the text.

- What representations of the country (i.e. where the target language taught is used as L1) does the reader perceive through the embodied modes included in the particular text?

- What representations of the country (i.e. where the target language taught is used as L1) does the reader perceive through the disembodied modes included in the particular text?

(continued overleaf) 
Table 3 (cont): An overview of the MIRRORFramework

Represented social interpretation (per individual text);

- Are particular social features and practices preferred/disfavored by this particular text?

- Are particular discourses preferred/disfavored by this particular text?

Overview of the representations of the country where the target language taught is used as L1 observed: presenting a detailed write up of the representations of the country where the target language taught is used as L1 obtained per individual text. Later comparing individual trends with common trends derived from texts as a whole (where possible)

- Amalgamating different parts of the particular text - therefore treating the particular text as a whole - which representations of the country where the target language taught is used as L1 feature throughout the series?

- At any point, is/are there any contradicting representation(s) featuring in this particular series?

Reorganising the representations of the country (i.e. where the target language taught is used as L1) derived from the MIRROR Framework (i.e. those presented in the above-mentioned steps) under the different categories proposed by the FL curriculum of the particular learning context where the text is being used.

\section{References}

Beach, R. and O'Brien, D. (Eds) (2008), Teaching popular culture texts in the classroom. Mahwah, NJ: Erlbaum.

Block, D. and Cameron, D. (2002). Globalization and language teaching. London: Routledge. Available [Online] at: http://www.dawsonera.com/depp/athens?url=http://www.dawsonera.com/depp/reader/protected/e xternal/AbstractView/S9780203193679.

Blommaert, J. (2005). Discourse: a critical introduction. Cambridge: Cambridge UP.

Brown, G. and Yule, G. (1983). Discourse Analysis. Cambridge: Cambridge University Press.

Byram, M. (Ed.) (1993), Germany - Its Representation in Textbooks for Teaching German in Great Britain. Frankfurt: Verlag Moritz Diesterweg.

Dwyer, D. (2009). Interpersonal Relationships. London: Routledge.

Fairclough, N. (2003). Analysing discourse: textual analysis for social research. London: Routledge.

Fairclough, N. (2010 [2008]). 'A dialectical-relational approach to critical discourse analysis'. In N. Fairclough (Ed.), Critical Discourse Analysis: The Critical Study of Language. (pp. 230-254). Harlow, UK: Longman.

Gibson, J. J. (1979). The Ecological Approach to Visual Perception. Boston, MA: Houghton Mifflin.

Gruber, H. (1991). Antisemitismus and Mediendiskurs. Die Affäre "Waldheim" in der Tagespresse. Wiesbaden: Deutscher Universitätsverlag.

Habermas, J. (1984). The theory of communicative action. London: Heinemann Education.

Kress, G. (2010). Multimodality: a social semiotic approach to contemporary communication. London: Routledge. Available [Online] at: http://www.dawsonera.com/depp/athens?url=http://www.dawsonera.com/depp/reader/protected/e xternal/AbstractView/S9780203970034.

Kress, G. and Van Leeuwen, T. (2001). Multimodal discourse: the modes and media of contemporary communication. London; New York: Arnold; Oxford UP.

Kress, G. and Van Leeuwen, T. (2006). Reading images: the grammar of visual design. (2nd ed.). London: Routledge.

Krzyzanowski, M. and Oberhuber, F. (2007). (Un)Doing Europe. Bern: Peter Lang. 
Mitten, R. (1992). The Politics of Antisemitic Prejudice: The Waldheim phenomenon in Austria. Boulder, CO: Westview Press.

Norris, S. (2004). Analyzing multimodal interaction: a methodological framework. New York; London: Routledge.

O'Regan, J. P. (2006). 'The Text as a Critical Object: On theorising exegetic procedure in classroombased critical discourse analysis'. Critical Discourse Studies, 3 (2), 179-209.

Stein, P. (2008). Multimodal pedagogies in diverse classrooms: representation, rights and resources. London: Routledge. [Online] Available at: http://www.dawsonera.com/depp/athens?url=http://www.dawsonera.com/depp/reader/protected/e xternal/AbstractView/S9780203935804.

Sutherland, J. (2006). 'Promoting group talk and higher-order thinking in pupils by coaching secondary English trainee teachers'. Literacy, 40 (2), 106-114.

Triandafyllidou, A., Wodak, R. and Krzanowski, M. (2009). European Media in Crisis and the European Public Sphere. Basingstoke: Palgrave.

Wodak, R. (2009). 'Politics as Usual': The discursive construction and representation of politics in action. Basingstoke: Palgrave.

Wodak, R., Nowak, P., Pelikan, J., Gruber, H., de Cillia, R. and Mitten, R. (1990). 'Wir sind alle unschuldige Täter!': Diskurshistorische Studien zum Nachkriegsantisemitismus. Frankfurt am Main: Suhrkamp.

Wood, K. D. and Blanton, W. E. (2009). Literacy instruction for adolescents: Research based practice. New York: Guilford.

Zu, L. and Kong, Z. (2009). 'A Study on the Approaches to Culture Introduction in English Textbooks'. English Language Teaching, 2 (1), 112-118.

Received: 02/07/2016

Accepted: 01/02/2017 